\title{
Taste preferences, liking and other factors related to fruit and vegetable intakes among schoolchildren: results from observational studies
}

\author{
Johannes Brug ${ }^{1}$, Nannah I. Tak ${ }^{1}$, Saskia J. te Velde $^{1}$, Elling Bere ${ }^{2}$ and Ilse de Bourdeaudhuij ${ }^{3}$ \\ ${ }^{1}$ EMGO Institute, VU University Medical Centre, Amsterdam, The Netherlands \\ ${ }^{2}$ Agder University College, Kristiansand, Norway \\ ${ }^{3}$ Department of Movement Sciences, Ghent University, Belgium
}

The present paper explores the relative importance of liking and taste preferences as correlates of fruit and vegetable (FV) intakes among schoolchildren in Europe. The paper first provides an overview of potential determinants of food choice among children and subsequently summarizes the results of two recent observational studies on determinants of FV intakes among school-aged children. It is proposed that taste preferences and liking are important for children's food choices as part of a broader spectrum of nutrition behaviour determinants. Taste preferences and liking are important for motivation to eat certain foods, but social-cultural and physical environmental factors that determine availability and accessibility of foods, as well as nutrition knowledge and abilities should also be considered.

Study 1 shows that children with a positive liking for FV have a greater likelihood to eat fruits (odds ratio $(\mathrm{OR})=1.97)$ or vegetables $(\mathrm{OR}=1.60)$ every day, while ability and opportunity related factors such as knowledge, self-efficacy, parental influences and accessibility of FV were also associated with likelihood of daily intakes (ORs between 1.16 and 2.75). These results were consistent across different countries in Europe. Study 2 shows that taste prerences were the stongest mediator of gender differences in FV intakes among children; the fact that girls eat more could for a large extend be explained by there stronger taste preferences.

Fruit and vegetables: Taste preferences: Determinants of food choice

Diet and nutrition clearly play a critical role during childhood and adolescent development. First of all, children and adolescents need to cover not only their nutrient and energy needs for maintenance metabolism and physical activities, but also for growth $^{(1)}$. Furthermore, eating habits may be less established in childhood and adolescence, and may therefore be better modifiable ${ }^{(2)}$, and food preferences and habits adopted in childhood and adolescence may track to a certain extend into adulthood ${ }^{(3-5)}$.

Nutritional habits are not in line with recommendations among children and adolescents. Many young people eat not enough fruits and vegetables, too much saturated fat, and more energy than they need ${ }^{(6)}$. In order to promote more healthful eating, we need to know why children and adolescents eat what they eat ${ }^{(7,8)}$.

What, when and how much children eat is influenced by a complex, interrelated set of so-called behavioural 'determinants' and successful dietary behaviour change interventions are dependent on the identification of the most important and best changeable determinants, because intervention strategies, methods and materials need to be selected or developed that are tailored to the target populations and to the most important and best modifiable determinants of behaviour change.

In this paper we will first give a brief overview of different important categories of determinants of food choice and dietary intake among children and adolescents. Secondly, we will present and discuss the results of two recent observational studies on determinants of fruit and vegetable (FV) intakes that illustrate the relative importance of taste preferences and liking as compared to other potential determinants of FV consumption among school-aged children across Europe ${ }^{(9)}$.

\section{Determinants of food intake: motivation, ability and opportunity}

In affluent countries, most people can generally choose what, when and how much they eat. To induce dietary change, one needs to change people's food choices. Studies on personal determinants of food choice have primarily made use of psychological theories to explain food choice and nutrition behaviours $^{(10)}$. It has, however, been argued that, since children may have less autonomy in making food choices, environmental rather than personal factors may be more important determinants of their nutrition behaviours. More recently, social-ecological models of health behaviour ${ }^{(11)}$ have drawn more attention to such environmental influences on nutrition behaviours. A framework proposed by Rothschild $^{(12)}$ provides a simple, integrative framework to categorise the large and diverse number of potential personal and environmental determinants from various more specific 
behaviour theories. Rothschild identifies three distinct categories of determinants: motivation, ability and opportunity. These categories of determinants are interrelated. For example, in environments with few opportunities for healthful eating, higher motivation and more abilities are needed to maintain a healthful diet.

\section{Motivation}

Behavioural decision, motivation or intention have been identified as primary determinants of behaviour ${ }^{(13)}$. Motivation or intention is influenced by a subjective weighing of expected positive and negative consequences of the behaviour. In general, expectations about short-term outcomes are more important than longer-term outcomes. Taste, satiety and pleasure are short-term consequences of major importance. Taste preferences and liking are regarded as key determinants of food choice $^{(14)}$. People, and young people maybe more so, eat what they like, and disliked foods are avoided ${ }^{(2)}$. Certain taste preferences are innate, such as a liking for sweet and salt, and a dislike for bitter and sour. However, taste preferences can be learned and unlearned ${ }^{(15)}$. 'Hunger' or appetite is also a strong motivator to eat. In Maslov's hierarchy of human needs, the need to cover physiological energy requirements, i.e. overcoming hunger, is among the highest human priorities, and the urge to eat and drink when hungry is an inborn trait.

Since eating is primarily a way to cover the basic physiological nutrient requirements and calorie requirements, satiety, i.e. the feeling that energy requirements have successfully been met, is a strong reinforcer for eating specific foods and we therefore quickly learn to like and appreciate energydense foods ${ }^{(2)}$. Children are therefore 'programmed' to like, or to learn to like, the taste of high-energy, sweet and fatty foods. Nevertheless, many acquire a taste for coffee, tea or beer during childhood and adolescence, which shows that we can even unlearn our innate dislike of bitter.

Some specific types of taste preference learning strategies have been identified. The aforementioned example of learning to like high-energy foods is referred to as 'taste-nutrient learning'. Taste-nutrient learning is an example of operant or instrumental conditioning: a stimulus (eating energy dense, sweet and fatty food) is positively reinforced ('rewarded') by the pleasant feeling of satiety. In the last decades palatable energy-dense foods have become readily available and accessible for most children in western countries. This abundance combined with our innate preference for energy-dense foods may be an important cause for the present-day obesity epidemic. Research shows that high-fat and sugar-rich foods are indeed among the most preferred foods among children and adolescents ${ }^{(16)}$. Most fruits and especially vegetables have low-energy densities, and many vegetables have a somewhat bitter taste. Preferences for these foods are therefore not so easily learned.

Two other food preference-learning strategies are examples of classical conditioning and are referred to as 'taste-taste learning' and 'taste-environment learning'. If a new, unfamiliar, taste is combined with a taste for which a preference already exists, children will more easily learn to like the new taste. For example, children will more easily learn to like the somewhat bitter taste of tea or the sour taste of yoghurt or grapefruit, if these are first served with sugar. Similarly, a liking for tastes that people are exposed to in pleasant physical or social environments are also learned. Foods first encountered as a child in a friendly, pleasant family environment, may become favourite foods for a lifetime.

A fourth important learning strategy is observational learning or modelling: children learn to like the taste of foods that they see their parents, siblings, friends or other 'important others' eat.

Health related beliefs may also be important. If people are asked about what they find important in their diet and food choice, 'health' usually comes second (or third) after 'taste' (and cost), especially among women ${ }^{(17)}$. Nevertheless, $40 \%$ of Americans and $57 \%$ of Europeans indicated rarely or never to compromise on taste to improve the healthfulness of their diets ${ }^{(18)}$. This is probably even more likely among children $^{(19)}$.

Motivation and intentions are important determinants of nutrition behaviours, and taste preferences and liking importantly influence motivation to eat. But not all behaviour is intentional, and we not always act on our intentions ${ }^{(20)}$. Lack of abilities or lack of environmental opportunities can be important barriers. Environmental cues may also trigger automatic behavioural responses.

\section{Ability}

Self-efficacy, or perceived behavioural control $(P B C)$, refers to one's confidence in one's abilities and skills to engage in certain behaviour. PBC is behaviour and context specific. A person can, for example, be confident to be able to eat less fat, but not to increase vegetable intake; and confidence to cut back on fat may be high for regular meals prepared at home, but not for eating out. PBC is strongly related to abilities and skills. Studies in children and adolescents show that food and nutrition-related self-efficacy is associated with healthful food choices and dietary behaviour ${ }^{(21-23)}$. Skills and abilities are to some extent dependent on practical knowledge. For example, knowing why to eat healthfully, knowing what healthful foods are, and knowing the recommended intake levels may all be conditional for voluntary healthful eating. Although knowledge in itself is unlikely to result in healthful food and nutrition choices - knowledge may be a necessary but insufficient condition for healthy food choice ${ }^{(19)}$ - some recent studies show that knowledge of recommended intake levels of $\mathrm{FV}$ was associated with higher intakes in 11-year old school children ${ }^{(23)}$.

\section{Environmental opportunities}

Children and adolescents' opportunities to make healthful dietary choices strongly depend on the opportunities their environments have to offer. For example, children's social environment, such as their parents and school staff, importantly influences their range of food choices; their physical environment, such as where they live or go to school, importantly influences what foods are available and accessible to them.

\section{Classifying the food environment}

The ANGELO framework ${ }^{(24)}$, which was specifically developed to conceptualise health behaviour environments related 
to obesity, distinguishes four 'types' of environments: physical, economic, political and socio-cultural. The physical environment refers to availability of healthy and unhealthy choices, such as points-of-purchase for FV and soft drink vending machines in schools. The economic environment refers to the costs related to healthy and unhealthy behaviours, such as the price of soft drinks, FV or energy-dense snacks in school cafeterias. The political environment refers to the rules and regulations that may influence food choice and eating behaviour. Bans on soft drink vending machines in schools, rules on what treats can and cannot be brought to school, as well as family food rules are micro-level political environmental factors. Other examples are national school food policies or national legislation regarding food-marketing efforts aimed at children. The socio-cultural environment refers to the social and cultural subjective and descriptive norms and other social influences such as social support for adoption of health behaviour and social pressure to engage in unhealthy habits.

Evidence for environmental determinants of nutrition behaviours in youth

Child and adolescent dietary behaviour is likely to be strongly influenced by environmental factors, since children may have less autonomy in food choice. From the age of about three years, children's eating behaviour is influenced by their responsiveness to environmental cues, and a variety of family and social factors start to influence children's eating behaviours ${ }^{(25)}$. The role of parents and schools is considered to be of particular importance.

\section{Parent and family influences}

Parents directly and importantly determine the child's microlevel social, political, physical as well as economical nutrition environments. Eating is a social behaviour, especially for children $^{(2)}$, and observing eating behaviours of others, especially parents, influences their own preferences and behaviour. Such modelling of eating behaviours can even result in establishing preferences for foods or substances that are inherently disliked. A recent review of the literature on environmental correlates of nutrition behaviours in youth indicates that children and adolescents' nutrition behaviours are consistently associated with their parents' behaviours ${ }^{(26)}$. Parents further influence their offspring's nutrition behaviours by actively encouraging, discouraging or controlling certain behaviours. Restricting children's access to, for example high fat or sugar-rich foods, may encourage rather than discourage preferences for such foods, especially if these same foods are also used to reward children for good behaviour and for celebrations ${ }^{(2)}$. However, a study conducted in Belgium indicated that clear restrictive family rules about high fat foods during childhood were associated with healthier food choices in adolescence ${ }^{(27)}$, and a recent cross-European study showed that parental demand as well as facilitation to eat FV were associated with higher intake levels in 11 year old children, while 'parental allowance' (i.e. parents allowing children to eat as much as they like), was not ${ }^{(23,28)}$

From studies on the association between general parenting styles and children's health behaviours, it appears that authoritative parenting, i.e. a parenting style characterised by high parental involvement as well as strictness, is associated with more positive health behaviours including higher FV intakes ${ }^{(29,30)}$, compared to adolescents who reported authoritarian (high strictness, low involvement) or neglectful (low strictness, low involvement) parenting styles.

As a result of these parenting practices and rules, as well as parents' own food preferences and choices, parents influence what foods are available and accessible within the home environment. Availability and accessibility of foods have repeatedly been found to be associated with intake levels in children and adolescents ${ }^{(31)}$.

Finally, family socio-economic position is important. A recent review of the literature confirmed that low parental education, as well as parental income is associated with less healthful diets in children and adolescents ${ }^{(32,33)}$.

\section{School influences}

A second important setting for children and adolescent nutrition is the school environment. Children spend much time at school; consume a large proportion of their daily intakes there, and schools offer nutrition education as part of the regular curriculum.

Accessibility and availability of foods in schools are important physical environmental factors. In many countries across Europe, schools provide lunch or other foods for the students, with great differences between countries. For example, in Belgium school lunches are offered in a majority of primary and secondary schools. Parents need to pay for their children to have a school lunch, children are allowed to bring their own lunch to school, and the school lunches are not required to meet official dietary guidelines. Most secondary schools do have vending machines and snack food outlets. In The Netherlands, a neighbouring country, school lunches are not offered. In primary schools, children go home for lunch or children need to bring their lunch to school. In secondary schools, adolescents bring their lunch to school, or they can buy lunch in the school a la carte cafeteria. In Sweden and the UK primary and secondary schools do offer free school lunches but while Swedish schools are required to meet official recommended intake levels, nutrition requirements for school lunches in the UK only state that meals in primary schools should contain at least one item from four major food groups (starchy foods; FV; dairy products; meat, fish or alternative protein source) and in secondary school lunches at least two items from each of these groups should be offered. Preliminary evidence from the European Pro Children study indicates that school lunches can make a difference; Swedish kids eat more vegetables at school than children from other countries across Europe, and have a relatively high total daily vegetable intake.

\section{Macro-level environment}

An important macro-level factor is how foods are marketed to children and adolescents. Children and adolescents are increasingly seen as an important target group for food marketing ${ }^{(34)}$. Young people in affluent countries have money to spend themselves, they may also influence food-buying behaviours of their parents, and they are the future adult buyers and consumers. Foods that are most intensively marketed by 
means of advertisement and marketing campaign are foods that are high in sugar and fats, and often low in micronutrients. In the US fast food restaurants and soft drink companies spent most on marketing their products. The large portion sizes offered at 'value pricing' (i.e. larger portions cost relatively less), especially in the US, is a marketing strategy that has probably contributed to higher caloric intakes and unnecessary weight gain. Television still is the most important channel for marketing food products, especially for younger children, but food marketing among youth also includes, for example, school-based marketing, Internet advertising, and sponsoring of events. Recent research confirmed that food adverts exposure promotes consumption and that obese children in particular have heightened responsiveness to these food-promotion adverts ${ }^{(35)}$.

Although most countries do regard children as a special vulnerable group for television advertising, there are striking differences between countries in rules and regulations for food marketing to children. Only few countries have a complete ban on television advertising for younger children. But most countries ( $85 \%$ of 73 countries surveyed by the WHO) do have statutory regulations for food television advertising to children; regulations that define, for example, in what ways foods can be promoted at what broadcasting times. The principle underlying many regulations is that advertising may not be misleading. At the ministerial conference on counteracting obesity organised by WHO Europe, all ministers of countries in the European region signed a charter in which they recognized the importance of marketing ${ }^{(36)}$.

\section{The relative importance of liking and preferences: evidence from observational studies}

To explore how important taste-preferences and liking are as population correlates of food intakes among children two recently published studies on correlates of FV intakes, the Pro Children study and the Fruits and Vegetables Make the Mark study are illustrative ${ }^{(28,37)}$.

\section{The Pro Children project}

A cross-sectional survey was conducted as part of the Pro Children project in nine European countries (Austria, Belgium, Denmark, Iceland, The Netherlands, Norway, Portugal, Spain and Sweden) during October - December 2003.

Schools constituted the sampling unit, and from each country random samples of at least 20 schools and a minimum of 1300 11-year old eligible children were recruited. A participation rate of $90.4 \%$ was reached in the participating schools; mean age was 11.4 years (range $8 \cdot 8-13.8, \mathrm{SD}=0.48 ; 79 \%$ of the children was born in 1992). The final sample sizes varied from 1105 for The Netherlands to 2134 for Portugal, with a total sample size of 13305 . A detailed description of the Pro Children project, including the sampling and data collection procedure is given elsewhere ${ }^{(6,9)}$. All protocols and questionnaires of the Pro Children projects can be accessed at www.prochildren.org

A self-report questionnaire in all applicable languages was developed to measure FV intake, and possible determinants informed by a social-ecological model ${ }^{(9)}$, a literature review $^{(38)}$, focus group interviews with children ${ }^{(39)}$, individual interviews with parents and school staff, and thorough pretesting as well as a rigorous translation - back translation procedure $^{(39,40)}$. The questionnaire included questions that were analogous for FV intake on motivational factors such as liking and preferences, and attitudes; ability-related factors such as knowledge of recommended intake levels, self-efficacy and perceived barriers. The questionnaire also included items on opportunity-related factors related to the social-cultural environment: parental and peer modeling, active parental encouragement, parental demands to eat $\mathrm{FV}$, whether parents allow the child to eat as much FV as they like (parental allowances), whether parents actively facilitate FV intake by preparing/cutting FV (parental facilitation) and by giving their children FV to bring to school; and related to the perceived physical environment: availability of $\mathrm{FV}$ at home, at school, and at friends' home. An overview of the items, constructs, scaling and psychometrics is reported elsewhere ${ }^{(40,41)}$. Usual FV intake was measured using a validated food-frequency questionnaire $(\mathrm{FFQ})^{(42)}$.

Multilevel logistic regression analysis was used to investigate the associations of daily fruit (dichotomous) intake and daily vegetable intake (dichotomous) with the different motivational, ability and opportunity factors. The predictors were also dichotomized into 0 (negative or neutral, response category -2 to 0.49 ) or 1 (positive, response category $>0.49)^{(41)}$. Adjusted odds ratios (OR) and $98 \%$ confidence intervals (CI) were calculated for the total sample, both gender groups and all nine countries separately ${ }^{(28)}$.

\section{Differences in daily intake of $F V$}

In the total sample $43.2 \%$ of the children reported to eat fruit every day, $46 \cdot 1 \%$ reported to eat vegetables every day. A significant gender difference was found for both outcome measures: $47.7 \%$ of the girls and only $38.9 \%$ of the boys reported to eat fruit daily (OR:1.44, 98\% CI:1.33-1.56), while $51.8 \%$ of the girls and $40.5 \%$ of the boys reported to eat vegetables every day (OR:1.58, $98 \%$ CI:1.45-1.71). Significant differences were also found between the nine participating countries $(p<0.001)$. For daily fruit intake, the lowest rates were found in the Nordic countries of Norway, Iceland and Sweden, while the highest proportion of children with daily fruit intake was found in Portugal. For daily vegetable intake, low rates were again found in Norway, Iceland and Spain, and the highest rates were in The Netherlands, Belgium and Portugal.

\section{Correlates of daily FV intakes}

For daily fruit intake, motivation, ability as well as opportunity factors appeared to be of relevance. Daily fruit intake was more likely to be reported by children with a positive liking for fruit, with a preference for many different fruits and a positive attitude towards fruit intake. Furthermore, daily fruit intake was more likely among children who knew the national recommendation for fruit intake and with positive self-efficacy. In addition, 4 of the 6 social-environmental factors yielded significance. Daily fruit intake was more likely to be reported by children who experienced positive role models, by those with parents who demand them to eat fruit every day, by children with parents who facilitate fruit intake by cutting 
up fruit, and by those bringing fruit to school. None of the physical environmental factors was significantly associated with likelihood of daily intake (see Table 1).

Daily vegetable intake was also related to a positive liking of the taste of vegetables, a preference for different vegetables and a positive attitude towards vegetable consumption. Knowing the national guidelines for adequate vegetable intake and a positive self-efficacy to eat vegetables were also significantly associated with daily vegetable intake. All six socialenvironmental factors were significantly associated with eating vegetables every day. Finally, children who frequently have available vegetables they like at their home were more likely to report daily vegetable consumption.

In country specific analyses a preference for many fruits was significant in 5 out of 9 countries, a liking of the taste of fruit in 3 countries. Regarding ability-related factors, knowledge of the recommendation was significant in all countries, and in 7 countries daily fruit intake was significantly associated with positive self-efficacy. Of the opportunity-related factors, modeling was significant in all countries, bringing fruit to school was significant in 8 of the 9 countries, and parental demand to eat fruit daily was significant in 6 countries.

Liking the taste of vegetables was significantly associated with daily vegetable intake in 6 out of 9 countries, while preference for many vegetables was significant in 8 countries. Among the ability-related factors, self-efficacy and knowledge of recommendations yielded significance in 6 and 5 countries respectively. Parental demand ( 7 countries) and modeling (5 countries) were the opportunity factors that were positively associated with daily vegetable intake in a majority of countries (see Table 1).

These analyses indicate that liking and preferences are associated with daily intake of FV among school-aged children in Europe. However, other factors related to ability and opportunity were also important with effect sizes of a similar magnitude as preferences and liking. Effect sizes were in general somewhat larger for fruit intake than for vegetable intake.

\section{Gender differences and liking FV: Fruit and Vegetables Make the Marks (FVMM)}

A recent comprehensive review of studies on determinants of children's FV intake stated that gender is among the strongest determinants of adolescents' FV intake ${ }^{(38)}$; in 14 of 17 reviewed European studies girls reported to eat more FV than boys. A study was conducted to explore why boys eat less FV than girls and if differences in preferences for these foods explain consumption differences between boys and girls.

This study was part of the FVMM intervention project including 38 randomly selected elementary schools in two Norwegian counties. The pupils within the 20 control schools were used for the study presented here ${ }^{(37)}$. Data from survey questionnaires completed in May 2002 and May 2005 were used for the analyses. The questionnaire surveys were completed by the pupils in the classroom in the presence of a trained project worker, within one school-lesson (45 minutes). The FVMM control group is a cohort of 896 pupils (response $84 \%$ ), of which 813 and 728 respectively participated in the May 2002 (mean age 12.5) and May 2005 (mean age 15.5) surveys and also reported same gender at both surveys.

FV intake was measured with a validated short FFQ comparable to the Pro Children Study ${ }^{(43)}$. Potential mediators for the gender differences in intakes were motivation-related (preferences for FV; intention to eat 5-a-day), ability-related (self-efficacy to eat 5-a-day, knowledge about the 5-a-day recommendation) and opportunity-related (accessibility of

Table 1. Odds ratios $\left(\mathrm{ORs}^{1}\right)$ and $98 \%$ confidence intervals $(\mathrm{Cl})$ derived from multilevel logistic regression analyses of the Pro Children Study with daily fruit and vegetabale intakes as dependent variables and motivation, ability and opportuinty factors as independent variables

\begin{tabular}{|c|c|c|}
\hline & Daily fruit intake $(n=13168)$ OR $(98 \% \mathrm{Cl})$ & Daily vegetable intake $(n=11905)$ OR $(98 \% \mathrm{Cl})$ \\
\hline \multicolumn{3}{|l|}{ Motivation } \\
\hline Liking & $1.97(1.52-2.55)$ & $1.60(1.41-1.80)$ \\
\hline Preferences & $2.09(1.79-2.43)$ & $1.46(1.30-1.63)$ \\
\hline Attitudes & $1.36(1.14-1.63)$ & $1.16(1.03-1.31)$ \\
\hline \multicolumn{3}{|l|}{ Ability } \\
\hline Knowledge & $2.25(2.03-2.49)$ & $1.41(1.26-1.58)$ \\
\hline General self-efficacy & $0.88(0.64-1.20)$ & $0.82(0.68-1.00)$ \\
\hline Perceived barriers & $1.74(1.44-2.11)$ & $1.83(1.65-2.02)$ \\
\hline \multicolumn{3}{|l|}{ Opportunity } \\
\hline \multicolumn{3}{|l|}{ Social-environment } \\
\hline Modelling & $1.95(1.74-2 \cdot 19)$ & $1.43(1.29-1.60)$ \\
\hline Active parental encouragement & $0.96(0.85-1.08)$ & $1 \cdot 26(1 \cdot 12-1 \cdot 41)$ \\
\hline Demand family rule & $1.60(1.42-1.81)$ & $1.50(1.34-1.68)$ \\
\hline Allow family rule & $0.85(0.73-1.00)$ & $1.22(1.07-1.40)$ \\
\hline Family facilitation & $1.34(1.20-1.51)$ & $1.16(1.03-1.31)$ \\
\hline Bring FV to school & $2.75(2.43-3.12)$ & $1.99(1.68-2.36)$ \\
\hline \multicolumn{3}{|l|}{ Physical-environment } \\
\hline Availability at home & $1.22(1.00-1.48)$ & $1 \cdot 27(1 \cdot 12-1 \cdot 44)$ \\
\hline Availability at school & $1.00(0.88-1.13)$ & $1.08(0.95-1.22)$ \\
\hline Availability at friends house & $1.07(0.96-1.19)$ & $1.00(0.90-1.11)$ \\
\hline
\end{tabular}

${ }^{1}$ ORs are adjusted for gender, school and country level. 
FV at home and modelling). These variables were assessed with one to five statements with response alternatives ranging from 'I fully disagree' to 'I fully agree', except for the knowledge question which had seven response alternatives (for details see $\left.{ }^{(44)}\right)$. These scales have been analysed showing good reliability ${ }^{(45)}$.

A variable functions as a mediator when it is associated with the dependent variable (FV intake) and with the indepenent variable, i.e. the potential distal determinant (gender), and when the association between the independent variable (gender) and the dependent variable (FV intake) becomes non-significant or weakens after controlling for the potential mediator ${ }^{(46)}$.

All analyses conducted were different mixed models of repeated measures (i.e. both 2002 and 2005 data were included in the same analyses), all adjusting for school and time (survey), using SPSS 14. The analyses carefully tested each of the steps necessary to establish mediation. The proportions mediated by the mediators were calculated by subtracting the adjusted relationship between gender and FV intake (e.g. $\tau^{\prime}$ ) from the unadjusted $(\tau)$, and dividing the sum by the unadjusted value (i.e. $\left.\tau-\tau^{\prime} / \tau\right)^{(47)}$.

Girls reported to eat FV more often than boys and reported significantly more positive values for all the potential mediators (see Table 2).

In the single mediation analyses all determinants mediated part of the gender differences, but only adjustment for preferences decreased the gender difference to a level below statistical significance (see Table 3). Preferences alone explained $81 \%$ of the gender difference. In the multiple mediation analyses the six mediators together explained $91 \%$ of the gender difference, with preferences contributing with the largest amount $(25 \%)$. In addition, perceived accessibility contributed with $10 \%$ of the explanation (data not shown).

\section{Discussion}

FV intakes among schoolchildren are associated with preferences and liking, and the differences in intakes between girls and boys is strongly mediated by preferences. However, preferences are certainly not the only potential determinant of intakes. Ability and opportunity related factors such as knowledge, self-efficacy, parental influences and accessibility of FV are also associated with daily intake. These results were consistent across different countries in Europe. Accessibility of FV further mediates gender differences in intakes and recent research indicates that socio-economic differences in schoolchildren's FV intakes are more strongly related to accesibility

Table 2. Gender differences in fruit and vegetable intake and in determinants of intake at the first measurement in 2002

\begin{tabular}{lccrrrr}
\hline & $\begin{array}{c}\text { Items in } \\
\text { scale }\end{array}$ & Range & Boys & Girls & diff. & $p$-value \\
\hline FV intake & 4 & $0 / 40$ & 11.9 & 14.5 & 2.6 & $\leq 0.001$ \\
Accessibility & 5 & $-10 / 10$ & 3.6 & 4.9 & 1.4 & $\leq 0.001$ \\
Modelling & 4 & $-8 / 8$ & 2.5 & 3.1 & 0.7 & $\leq 0.001$ \\
Intention & 1 & $-2 / 2$ & -0.1 & 0.2 & 0.3 & 0.003 \\
Preferences & 4 & $-8 / 8$ & 1.3 & 2.9 & 1.5 & $\leq 0.001$ \\
Self-efficacy & 3 & $-14 / 14$ & 0.1 & 0.8 & 0.7 & $\leq 0.001$ \\
Knowledge & 1 & $0 / 6$ & 3.5 & 3.7 & 0.2 & 0.008 \\
\hline
\end{tabular}

Table 3. Single mediator analyses: effect of gender on FV intake after adjusting for accessibility, modelling, intention, preferences, self-efficacy OR knowledge

\begin{tabular}{|c|c|c|c|c|c|}
\hline & \multicolumn{5}{|c|}{ Models I } \\
\hline & \multicolumn{2}{|c|}{$\begin{array}{l}\text { Potential } \\
\text { mediator }\end{array}$} & \multicolumn{2}{|c|}{ Gender } & \multirow{2}{*}{$\begin{array}{l}\text { Mediated } \\
\left(\tau-\tau^{\prime}\right) / \tau\end{array}$} \\
\hline & $\beta^{\prime}$ & $p \beta^{\prime}$ & $\tau^{\prime}$ & $p \tau^{\prime}$ & \\
\hline Accessibility & 0.9 & $\leq 0.001$ & 1.3 & $\leq 0.001$ & 0.49 \\
\hline Modelling & 0.8 & $\leq 0.001$ & $2 \cdot 1$ & $\leq 0.001$ & 0.20 \\
\hline Intention & 1.8 & $\leq 0.001$ & $1 \cdot 8$ & $\leq 0.001$ & 0.31 \\
\hline Preferences & 0.9 & $\leq 0.001$ & 0.5 & 0.19 & 0.81 \\
\hline Self-efficacy & $1 \cdot 1$ & $\leq 0.001$ & $1 \cdot 8$ & $\leq 0.001$ & 0.30 \\
\hline Knowledge & $1 \cdot 1$ & $\leq 0.001$ & $2 \cdot 3$ & $\leq 0.001$ & 0.10 \\
\hline
\end{tabular}

$\tau^{\prime}=$ difference in FV intake between boys and girls, while adjusting for single potential mediators.

$\beta^{\prime}=$ difference in the single potential mediators between boys and girls, while adjusting for FV intake.

Mediated $=$ proportion of the gender difference in fruit and vegetable intake mediated by the respectively factors.

differences than preference differences (Bere et al., unpublished data).

The fact that liking and preferences were related to likelihood of daily intake of both FV has been found in earlier studies ${ }^{(22,48-51)}$ and confirms the importance of these motivation-related factors among children. Repeated exposure to many different kinds of FV at early age might be a good strategy to improve liking ${ }^{(25,52)}$ and increased intakes have been found to be associated with increased liking (Tak et al., unpublished data). Especially parents can promote preferences for FV in such a way. The results indeed confirm earlier studies that show that parental social environmental factors are important for dietary behaviors among school-aged children ${ }^{(53)}$. In line with previous research, perceived modeling was a predictor of daily FV intake ${ }^{(25,50,54-56)}$. Such social learning strategies are also important for learning to like the taste of FV. Next to this rather 'passive' influence of parental modeling, more active parental encouragement and facilitation was also associated with daily intakes.

Knowledge of the prevailing recommendations was positively related to daily $\mathrm{FV}$ intake which indicates that teaching these recommendations in primary schools may help to promote daily intake. School and family influences are very important to influence taste preferences and liking of FV and therefore these are ideal settings for interventions.

Positive self-efficacy was another ability-related factor associated with daily FV intake. The literature is inconsistent about the relationship between self-efficacy and FV intake $^{(22,48,49,55,57)}$, probably due to different possible operationalisations of the self-efficacy construct. Self-efficacy can probably be improved by making FV as available and accessible as possible and thus improve opportunity factors, and the Pro Children Study indicates that bringing FV to school is a good strategy to encourage daily FV intakes.

In the present study only home availability appeared to be a significant physical environmental correlate of daily vegetable consumption but not of daily fruit intake, although the association was close to reaching statistical significance. Earlier studies consistently showed positive associations between availability and FV intakes ${ }^{(50,51,53,55,57,58)}$. 
Bere et al. confirmed that gender is a strong correlate of FV intake and additionally showed that the gender difference in FV intake could be explained by differences in preferences and asseccibility between boys and girls. That perceived accessibility is higher among girls might be due to the fact that parents raise their daughters in a different way than they raise their sons where foods are concerned, which is also illustrated by observations in the Pro Children study: parents of daughters were more involved in the intervention and participate more often in parental activities than parents of boys (Wind et al., unpublished data). That opportunities for girls to eat FV are better than for boys, might also result in higher motivational factors such as taste preferences. However, from this cross sectional study we cannot conclude on causal relationships between determinants.

The two observational studies and the literature indicate that a wide range of determinants are important in children's FV consumption. However, which determinants of FV are exacly the most important ones is still difficult to answer because determinants are interrelated and from a complex pattern.

\section{Conclusion}

The present paper showed that the framwork proposed by Rothshild can help to categorize important determinants of FV intake and dietary intake in general. Furthermore, we showed that motivation factors, such as preferences, are among the most important determinants of FV intake among adolescents and that differences in prefences could also explain discrepancies in FV intake levels between boys and girls.

Moreover, opportunities, such as availability and asseccibility of FV, are important as well and more research is needed to assess potential moderating roles of availabity and/of motivational factors.

\section{Conflict of interest statement}

None of the authors has any conflicts of interest to report.

\section{References}

1. Koletzko B, de la Guéronnière V, Toschke AM \& von Kries R (2004) Nutrition in children and adolescents in Europe: what is the scientific basis? Introduction. Br J Nutr 92, Suppl. 2, S67-S73.

2. Birch LL (1999) Development of food preferences. Annu Rev Nutr 19, 41-62.

3. Kelder SH, Perry CL, Klepp KI \& Lytle LL (1994) Longitudinal tracking of adolescent smoking, physical activity, and food choice behaviors. Am J Public Health 84, 1121-1126.

4. Lien N, Lytle LA \& Klepp KI (2001) Stability in consumption of fruit, vegetables, and sugary foods in a cohort from age 14 to age 21. Prev Med 33, 217-226.

5. te Velde SJ, Twisk JWR \& Brug J (2007) Tracking of fruit and vegetable consumption from adolescence into adulthood and its longitudinal association with overweight. $\mathrm{Br} J \mathrm{Nutr} \mathbf{9 8}$, 431-438.

6. Yngve A, Wolf A, Poortvliet E, et al. (2005) Fruit and vegetable intake in a sample of 11-year-old children in 9 European countries: the Pro Children cross-sectional survey. Ann Nutr Metab 49, 236-245.
7. Brug J, Oenema A \& Ferreira I (2005) Theory, evidence and Intervention Mapping to improve behavioral nutrition and physical activity interventions. Int J Behav Nutr Phys Act 2, 2.

8. Baranowski T, Baranowski J, Cullen KW, Marsh T, Islam N, Zakeri I, Honess-Morreale L \& de Moor C (2003) Squire's Quest!: dietary outcome evaluation of a multimedia game. Am J Prev Med 24, 52-61.

9. Klepp KI, Pérez-Rodrigo C, De Bourdeaudhuij I, et al. (2005) Promoting fruit and vegetable consumption among European schoolchildren: rationale, conceptualization and design of the Pro Children Project. Ann Nutr Metab 49, 212-220.

10. Conner M \& Armitage CJ (2002) The Social Psychology of Food. Buckingham, UK: Open University Press.

11. Sallis JF \& Owen N (2002) Ecological models of health behavior. In Health Behavior and Health Education: Theory, Research, and Practice, 3rd ed., pp. 462-484 [K Glanz, BK Rimer and FM Lewis, editors]. San Francisco: Jossey-Bass.

12. Rothschild ML (1999) Carrots, sticks, and promises: a conceptual framework for the management of public health and the social issue behaviors. J Mark 63, 24-37.

13. van Trijp HCM, Brug J \& van der Maas R (2005) Consumer determinants and intervention strategies for obesity prevention. In Food, Diet and Obesity, pp. 331-356 [DJ Mela, editor]. Woodhead Publishing in Food Science and Technology: Cambridge, UK.

14. Capaldi ED (1996) Why We Eat What We Eat: The Psychology of Eating, pp. 53-80 [ED Capaldi, editor]. Washington, DC: American Psychological Association.

15. Rozin P (1990) Development in the food domain. Dev Psychol 26, 555-562.

16. Cooke LJ \& Wardle J (2005) Age and gender differences in children's food preferences. Br J Nutr 93, 741-746.

17. Lennernäs M, Fjellström C, Becker W, Giachetti I, Schmitt A, Remaut de Winter A \& Kearney M (1997) Influences on food choice perceived to be important by nationally-representative samples of adults in the European Union. Eur J Clin Nutr 51, Suppl. 2, S8-S15.

18. Health Focus (2005) 2005 Health Focus US trend report. Health Focus International, St. Petersburg, FL. Available from www.healthfocus.com

19. Story M, Neumark-Sztainer D \& French S (2002) Individual and environmental influences on adolescent eating behaviors. $J$ Am Diet Assoc 102, Suppl. 3, S40-S51.

20. Sheeran P (2002) Intention-behavior relations: a conceptual and empirical review. In European Review of Social Psychology, vol. 12, pp. 1-36 [M Hewstone and W Stroebe, editors]. Chichester, UK: Wiley.

21. Heatey KR \& Thombs DL (1997) Fruit-vegetable consumption self-efficacy in youth. Am J Health Behav 21, 172-177.

22. Resnicow K, Davis-Hearn M, Smith M, Baranowski T, Lin LS, Baranowski J, Doyle C \& Wang DT (1997) Social-cognitive predictors of fruit and vegetable intake in children. Health Psychol 16, 272-276.

23. Wind M, De Bourdeaudhuij I, te Velde SJ, Sandvik C, Klepp KI, Due P \& Brug J (2006) Correlates of fruit and vegetable consumption among 11-year-old Belgian-Flemish and Dutch schoolchildren. J Nutr Educ Behav 38, 211-221.

24. Swinburn B, Egger G \& Raza F (1999) Dissecting obesogenic environments: the development and application of a framework for identifying and prioritizing environmental interventions for obesity. Prev Med 29, 563-570.

25. Patrick H \& Nicklas TA (2005) A review of family and social determinants of children's eating patterns and diet quality. J Am Coll Nutr 24, 83-92.

26. Brug J, Van Lenthe FJ \& Kremers SPJ (2006) Revisiting Kurt Lewin: how to gain insight into environmental correlates of obesogenic behaviors. Am J Prev Med 31, 525-529. 
27. De Bourdeaudhuij I \& Van Oost P (1996) De relatie tussen op jonge leeftijd aangeleerde voedingsregels en voedingskeuze in de adolescentie (The relation between in childhood acquired dietary habits and dietary choices in adolescence). Gedrag en Gezondheid 24, 215-223.

28. De Bourdeaudhuij I, te Velde SJ, Brug J, et al. (2007) Personal, social and environmental predictors of daily fruit and vegetable intake in 11-year-old children in nine European countries. Eur J Clin Nutr, advance online publication 16 May 2007; doi: 10.1038/sj.ejcn.1602794.

29. Kremers SPJ, Brug J, de Vries H \& Engels RCME (2003) Parenting style and adolescent fruit consumption. Appetite 41, 43-50.

30. Patrick H, Nicklas TA, Hughes SO \& Morales M (2005) The benefits of authoritative feeding style: caregiver feeding styles and children's food consumption patterns. Appetite 44, 243-249.

31. Cullen KW, Baranowski T, Owens E, Marsh T, Rittenberry L \& de Moor C (2003) Availability, accessibility, and preferences for fruit, $100 \%$ fruit juice, and vegetables influence children's dietary behavior. Health Educ Behav 30, 615-626.

32. Wardle J, Jarvis MJ, Steggles N, Sutton S, Williamson S, Farrimond H, Cartwright M \& Simon AE (2003) Socioeconomic disparities in cancer-risk behaviors in adolescence: baseline results from the Health and Behaviour in Teenagers Study (HABITS). Prev Med 36, 721-730.

33. van der Horst K, Kremers S, Ferreira I, Singh A, Oenema A \& Brug J (2007) Perceived parenting style and practices and the consumption of sugar-sweetened beverages by adolescents. Health Educ Res 22, 295-304.

34. Story M \& French S (2004) Food advertising and marketing directed at children and adolescents in the US. Int J Behav Nutr Phys Act 1, 3.

35. Halford JC, Boyland EJ, Hughes G, Oliveira LP \& Dovey TM (2007) Beyond-brand effect of television (TV) food advertisements/commercials on caloric intake and food choice of 5-7year-old children. Appetite 49, 263-267.

36. Brug J (2007) The European charter for counteracting obesity: a late but important step towards action. Observations on the WHO-Europe ministerial conference, Istanbul, November 15-17, 2006. Int J Behav Nutr Phys Act 4, 11.

37. Bere E, Brug J \& Klepp KI (2007) Why do boys eat less fruit and vegetables than girls? Public Health Nutr, In press.

38. Rasmussen M, Krolner R, Klepp KI, Lytle L, Brug J, Bere E \& Due P (2006) Determinants of fruit and vegetable consumption among children and adolescents: systematic review of the literature. Int J Behav Nutr Phys Act 3.

39. Wind M, Bobelijn K, De Bourdeaudhuij I, Klepp KI \& Brug J (2005) A qualitative exploration of determinants of fruit and vegetable intake among 10- and 11-year-old schoolchildren in the low countries. Ann Nutr Metab 49, 228-235.

40. De Bourdeaudhuij I, Klepp KI, Due P, Rodrigo CP, De Almeida MDV, Wind M, Krolner R, Sandvik C \& Brug J (2005) Reliability and validity of a questionnaire to measure personal, social and environmental correlates of fruit and vegetable intake in 10-11-year-old children in five European countries. Public Health Nutr 8, 189-200.

41. Sandvik C, De-Bourdeaudhuij I, Due P, et al. (2005) Personal, social and environmental factors regarding fruit and vegetable intake among schoolchildren in nine European countries. Ann Nutr Metab 49, 255-266.
42. Haraldsdottir J, Thorsdottir I, de Almeida MD, Maes L, Perez Rodrigo C, Elmadfa I \& Frost Andersen L (2005) Validity and reproducibility of a precoded questionnaire to assess fruit and vegetable intake in European 11- to 12-year-old schoolchildren. Ann Nutr Metab 49, 221-227.

43. Andersen LF, Bere E, Kolbjornsen N \& Klepp KI (2004) Validity and reproducibility of self-reported intake of fruit and vegetable among 6th graders. Eur J Clin Nutr 58, 771-777.

44. Bere E \& Klepp KI (2005) Changes in accessibility and preferences predict children's future fruit and vegetable intake. Int $J$ Behav Nutr Phys Act 2, 15.

45. Bere E \& Klepp KI (2004) Reliability of parental and selfreported determinants of fruit and vegetable intake among 6th graders. Public Health Nutr 7, 353-356.

46. Baron RM \& Kenny DA (1986) The moderator-mediator variable distinction in social psychological research: conceptual strategic, and statistical considerations. J Pers Soc Psych 51, 1173-1182.

47. MacKinnon DP (1994) Analysis of mediating variables in prevention and intervention research. In Scientific Methods for Prevention Intervention Research (NIDA research monograph no. 139 DHHS Pub. no. 94-3631). pp. 127-153 [A Cazares and LA Beatty, editors]. Washington, DC: US Department of Health and Human Services.

48. Domel SB, Thompson WO, Davis HC, Baranowski T, Leonard SB \& Baranowski J (1996) Psychosocial predictors of fruit and vegetable consumption among elementary school children. Health Educ Res 11, 299-308.

49. Lien N, Jacobs DR \& Klepp KI (2002) Exploring predictors of eating behaviour among adolescents by gender and socio-economic status. Public Health Nutr 5, 671-681.

50. Bere E \& Klepp KI (2004) Correlates of fruit and vegetable intake among Norwegian schoolchildren: parental and selfreports. Public Health Nutr 7, 991-998.

51. Neumark-Sztainer D, Wall M, Perry C \& Story M (2003) Correlates of fruit and vegetable intake among adolescents: findings from Project EAT. Prev Med 37, 198-208.

52. Wardle J, Herrera ML, Cooke L \& Gibson EL (2003) Modifying children's food preferences: the effects of exposure and reward on acceptance of an unfamiliar vegetable. Eur J Clin Nutr 57, $341-348$.

53. Hanson NI, Neumark-Sztainer D, Eisenberg ME, Story M \& Wall M (2005) Associations between parental report of the home food environment and adolescent intakes of fruits, vegetables and dairy foods. Public Health Nutr 8, 77-85.

54. Gibson EL, Wardle J \& Watts CL (1998) Fruit and vegetable consumption, nutritional knowledge and beliefs in mothers and children. Appetite 31, 205-228.

55. Young EM, Fors SW \& Hayes DM (2004) Associations between perceived parent behaviors and middle school student fruit and vegetable consumption. $J$ Nutr Educ Behav 36, 2-8.

56. Cullen KW, Baranowski T, Rittenberry L, Cosart C, Hebert D \& de Moor C (2001) Child-reported family and peer influences on fruit, juice and vegetable consumption: reliability and validity of measures. Health Educ Res 16, 187-200.

57. Reynolds KD, Hinton AW, Shewchuk R \& Hickey CA (1999) Social cognitive model of fruit and vegetable consumption in elementary school children. J Nutr Educ 31, 23-30.

58. Kratt P, Reynolds KD \& Shewchuk R (2000) The role of availability as a moderator of family fruit and vegetable consumption. Health Educ Behav 27, 471-482. 